
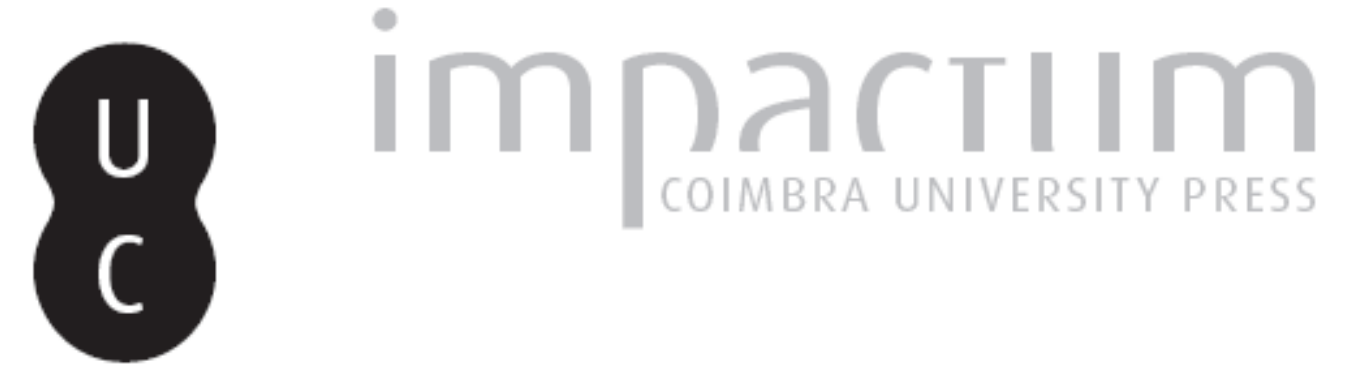

\title{
Decisão e acção na filosofia de Martin Heidegger
}

\section{Autor(es): $\quad$ Sá, Alexandre Franco de}
Publicado por: Faculdade de Letras da Universidade de Coimbra, Instituto de Estudos Filosóficos

URL

persistente:

URI:http://hdl.handle.net/10316.2/29520

DOI:

DOI:http://dx.doi.org/10.14195/0872-0851_40_1

Accessed : $\quad$ 26-Apr-2023 06:33:13

A navegação consulta e descarregamento dos títulos inseridos nas Bibliotecas Digitais UC Digitalis, UC Pombalina e UC Impactum, pressupõem a aceitação plena e sem reservas dos Termos e Condições de Uso destas Bibliotecas Digitais, disponíveis em https://digitalis.uc.pt/pt-pt/termos.

Conforme exposto nos referidos Termos e Condições de Uso, o descarregamento de títulos de acesso restrito requer uma licença válida de autorização devendo o utilizador aceder ao(s) documento(s) a partir de um endereço de IP da instituição detentora da supramencionada licença.

Ao utilizador é apenas permitido o descarregamento para uso pessoal, pelo que o emprego do(s) título(s) descarregado(s) para outro fim, designadamente comercial, carece de autorização do respetivo autor ou editor da obra.

Na medida em que todas as obras da UC Digitalis se encontram protegidas pelo Código do Direito de Autor e Direitos Conexos e demais legislação aplicável, toda a cópia, parcial ou total, deste documento, nos casos em que é legalmente admitida, deverá conter ou fazer-se acompanhar por este aviso.

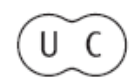




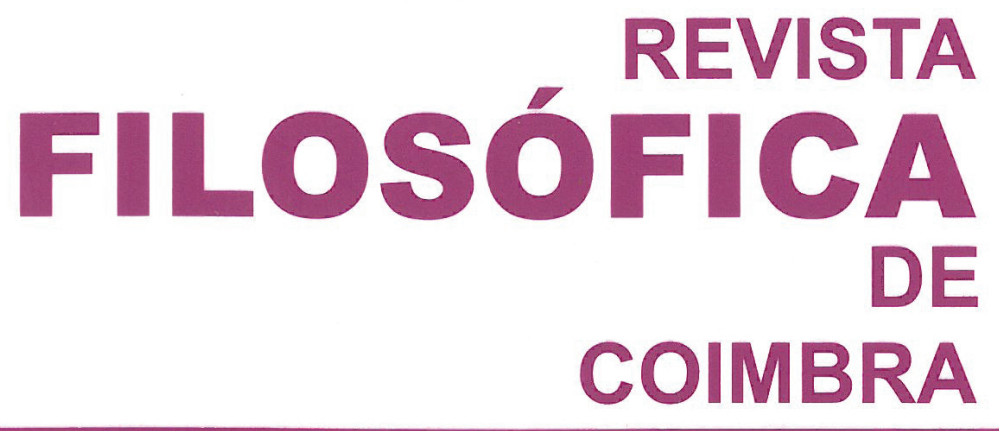

vol. 20 - número 40 - outubro 2011

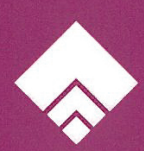




\title{
DECISÃO E ACÇÃO NA FILOSOFIA DE MARTIN HEIDEGGER
}

\author{
ALEXANDRE FRANCO DE SÁ1
}

\begin{abstract}
Resumo: O presente artigo propõe-se compreender o movimento do pensar heideggeriano entre as décadas de 1920 e de 1930 como uma tentativa de cumprir as expectativas de Heidegger na elaboração da ontologia fundamental. A transformação do conceito de decisão, passando da sua compreensão como expressão da resolução do Dasein (Entschlossenheit) para a sua compreensão como início (Anfang) de um mundo e de um tempo novo, torna-se aqui a base para entender o movimento do pensar de Heidegger.
\end{abstract}

Palavras-Chave: Heidegger, Decisão, Acção, Ontologia Fundamental

\begin{abstract}
The present paper conceives the movement of Heidegger's thinking between the Twenties of the Thirties as an attempt to fulfil Heidegger's expectations on the development of fundamental ontology. The transformation of the concept of decision, from its comprehension as the expression of Dasein's resolution (Entschlossenheit) to its comprehension as the beginning (Anfang) of a world and of a new time, becomes here the basis for understanding the movement of Heidegger's thinking.
\end{abstract}

Keywords: Heidegger, Decision, Action; Fundamental Ontology.

Se considerarmos a filosofia de Martin Heidegger sob a perspectiva daquilo a que a tradição filosófica chamou a filosofia prática, no sentido de filosofia da acção, poderíamos dizer que, em certa medida, esta é atravessada por um dilema fundamental. Um tal dilema é facilmente identificável. E ele torna-se manifesto a partir do contraste entre o per-

${ }^{1}$ Departamento de Filosofia, Comunicação e Informação, Faculdade de Letras da Universidade de Coimbra. 
curso de pensamento de Heidegger em torno daquilo a que ele chamou o projecto de elaboração de uma ontologia fundamental, tal como este é levado a cabo em Ser e Tempo e nas lições dos anos 20 que o rodeiam, por um lado, e, por outro lado, os matizes que caracterizam este mesmo pensamento no período posterior à tentativa de acabamento deste projecto, ou seja, no período que se inicia com a década de 1930 .

A partir da perspectiva aqui pretendida, dir-se-ia que, por um lado, considerando Ser e Tempo, o tema da decisão - e o conceito de estar-decidido ou, o que é o mesmo, de resolução (Entschlossenheit) - emerge genericamente como o pano de fundo de uma resposta preliminar à interrogação em torno do modo como o homem é chamado a existir autenticamente como ele mesmo. Por outras palavras: o "estar-decidido" do Dasein, a sua resolução (Entschlossenheit), aparece aqui como a referência a partir da qual o modo de existir a que Heidegger chama autenticidade (Eigentlichkeit) adquire aquilo a que se poderia chamar uma configuração concreta. Como escreve o próprio Heidegger no seguimento da abordagem do conceito de resolução: «A autenticidade do Dasein não é agora nem um título vazio nem uma ideia inventada» ${ }^{2}$; e ela já não o seria porque a resolução permitiria colocar como subjacente à análise «uma determinada concepção ôntica da existência autêntica, um ideal fáctico do Dasein» ${ }^{3}$.

Por outro lado, se considerarmos o pensamento de Heidegger tal como este se desenvolve na década seguinte à publicação de Ser e Tempo, torna-se manifesto que a decisão deixa de ter o significado de uma decisão individual de cada homem em torno do modo concreto como existe, passando antes a significar a inauguração de um campo de possibilidades através de uma cisão primordial, cisão essa que, escapando a qualquer dimensão de escolha subjectiva, se encontraria aquém daquilo que poderia ser humanamente decidido. É para a expressão desta cisão inaugural que Heidegger passa a usar o termo "decisão" escrito com hífen: de-cisão (Entscheidung). E o uso deste hífen significa que este termo alude agora ao recorte do campo de possibilidades de uma história cujo desencadeamento se caracteriza precisamente por não se encontrar nas mãos do homem. Daí que Heidegger, nos textos que marcam o seu pensamento da década de 1930, particularmente nas Contribuições para a Filosofia e nos textos e lições que giram em seu redor, seja muito claro em assinalar o carácter não humano da decisão primordial em que a existência humana, à partida, se situa: «Se falamos aqui de de-cisão, não pensamos num fazer [Tun] do homem, no levar a cabo [Vollziehen], num processo [Vorgang]. Não é aquilo que num acto é humano nem aquilo que é processual que aqui é

\footnotetext{
${ }^{2}$ Martin Heidegger, Sein und Zeit, Tübingen, Max Niemeyer, 1986, p. 301.

${ }^{3}$ Ibid., p. 310.
} 
essencial» ${ }^{4}$. E é esta alusão a uma decisão primordial que precede tudo o que o homem possa fazer que está na base das duas posições fundamentais que determinam o pensamento heideggeriano desenvolvido nesta década. Em primeiro lugar, um tal pensamento é marcado por constantes incursões interpretativas em Ser e Tempo, empreendidas com o propósito de o guardar diante daquilo a que o próprio Heidegger chama um «perigo» ${ }^{5}$ : o perigo de uma interpretação equívoca que o tomasse num registo subjectivista e antropológico. Em segundo lugar, este pensamento caracteriza-se pela evocação do ser como algo que, não podendo ser já compreendido satisfatoriamente a partir daquele que o compreende - o Dasein enquanto ser-aí -, tem antes de ser tomado como uma abertura primordial que, ao invés, compreende agora o próprio Dasein, não podendo deixar de se apropriar, para que ela própria seja, de um "aí" que a torne num acontecimento. É neste sentido que Heidegger começa aqui a escrever Sein com $y(S e y n)$, referindo-se-lhe como um Ereignis (termo que, tendo em conta a origem etimológica do termo alemão, julgamos traduzir adequadamente em português como o "acontecimento da apropriação" [Er-eignis]). E é neste mesmo sentido que o termo alemão para essência (Wesen) passa a ser usado por Heidegger com um sentido verbal, expressando o carácter primordial do ser do ser (do "essenciar-se" do ser; do Wesen des Seins) diante do ser do ente (das Sein des Seienden) enquanto aquilo que é. Como escreve Heidegger: $" \mathrm{O}$ ser essencia-se como acontecimento da apropriação. [...] O ente é. O Ser essencia-se. O Ser (como acontecimento da apropriação) precisa do ente para que ele, o Ser, se essencie» ${ }^{6}$.

São estas duas posições fundamentais do pensamento heideggeriano desenvolvido na década de 1930 que constituem o enquadramento no qual se torna imprescindível interrogar a relação do pensamento de Heidegger com a filosofia prática. Por um lado, Heidegger apresenta aqui explicitamente o ser como o fundo a partir do qual emerge uma decisão primordial não humanamente determinada. Como Heidegger escreverá em Meditação, na sequência das Contribuições para a Filosofia: "A decisão pertence à essência do próprio Ser e não é nada que seja feito pelo homem, pois este mesmo recebe a partir desta de-cisão e da sua recusa o carácter de fundamento e de fundador ou o carácter ocupado ou fugidio da sua essência. O Ser de-cide» ${ }^{7}$. Por outro lado, Heidegger procura explicitamente

${ }^{4}$ Martin Heidegger, Beiträge zur Philosophie (Vom Ereignis), Gesamtausgabe, vol. 65, Frankfurt, Vittorio Klostermann, 1989, p. 87.

5 Ibid.

${ }^{6}$ Ibid., p. 30.

${ }^{7}$ Martin Heidegger, Besinnung, Gesamtausgabe, vol. 66, Frankfurt, Vittorio Klostermann, 1997, p. 46. 
reinterpretar Ser e Tempo a partir desta alusão a uma de-cisão originária do ser anterior a qualquer decisão humana. Assim, se Heidegger procura reinterpretar a posição de Ser e Tempo à luz da evocação de uma decisão primordial que constitui, antes de todas as decisões humanas, uma decisão prévia, torna-se necessário perguntar - tomando a perspectiva da filosofia prática - se o que aqui está em causa, para Heidegger, não se pode traduzir afinal naquilo a que se poderia chamar uma diminuição da liberdade do homem. Comparando o pensamento exposto em Ser e Tempo com as considerações tecidas em torno das Contribuições para a Filosofia, será possível estabelecer, no pensamento de Heidegger, um dilema entre o apelo para a decisão, característico dos anos de 1920, e a alusão a uma prévia de-cisão do ser, isto é, a alusão a uma passividade humana diante de uma decisão primordial que já sempre previamente ocorreu, característica dos anos de 1930? Ou será que, pelo contrário, um tal dilema é algo meramente aparente e é possível encontrar, no percurso do pensamento de Heidegger, uma coerência que inviabiliza, a um nível mais profundo, o estabelecimento de dilemas desta natureza? É esta questão que servirá de fio condutor à reflexão que aqui nos propomos apresentar.

Para abordar adequadamente a questão formulada, não é possível deixar de revisitar, com a imprescindível brevidade, o projecto filosófico que anima Ser e Tempo: o projecto de constituição de uma ontologia fundamental. Um tal projecto consiste, como se sabe, numa tentativa de encontrar os fundamentos mais originários da tradição ontológica da filosofia ocidental, abordando os seus pressupostos impensados e as suas consequentes limitações, e na subsequente viabilização de uma construção fenomenológica que permitisse aquilo a que poderíamos chamar uma adequada articulação entre a unidade do ser e a multiplicidade do ente, espalhada por regiões ônticas ainda carecidas de uma tematização fenomenológica suficiente. À desobstrução de um acesso mais originário à tradição ontológica chama Heidegger uma "destruição" (Destruktion) desta mesma tradição: uma "destruição" não no sentido de uma aniquilação ou de uma substituição da tradição por uma "nova era" já não tradicional, mas no sentido de uma confrontação (aquilo a que Heidegger chamará uma Auseinandersetzung) que exclusivamente permitiria ao pensar a aquisição de uma posição própria. Por seu lado, à construção fenomenológica que deveria ser viabilizada pela "destruição" chama Heidegger, nas suas lições do semestre de Verão de 1928, uma "viragem" (Kehre) para a constituição de "ônticas metafísicas" ou de "metontologias"8 a partir das quais as várias regiões ônticas pudessem ser diferenciadas e tematizadas

${ }^{8}$ Cf. Metaphysische Anfangsgründe der Logik im Ausgang von Leibniz, Gesamtausgabe, vol. 26, Frankfurt, Vittorio Klostermann, 1978, p. 201. 
adequadamente sob o ponto de vista fenomenológico. As duas tarefas - a tarefa destrutiva e a tarefa construtiva - que constituiriam o projecto da ontologia fundamental deveriam poder ser sustentadas, segundo Heidegger, numa análise fenomenológica preparatória da constituição de ser (Seinsverfassung) do ente que se caracterizaria pela sua compreensão prévia do ser e, nesse sentido, pela sua constituição ontológica: o Dasein. É a esta análise preparatória que, como é sabido, Ser e Tempo se dedica. E que o projecto não tenha tido a continuidade prevista, dando motivo aos posteriores ensaios do próprio Heidegger de uma leitura mais originária de Ser e Tempo, terá de ser indício de uma dificuldade ou mesmo de uma inconsistência que, imanente ao próprio projecto ontológico-fundamental, não pode deixar de ser explicitada.

Mas onde se poderá encontrar, afinal, esta inconsistência? Penso que esta dificuldade ou inconsistência pode ser encontrada adequadamente no ponto da articulação entre a análise preparatória do Dasein que deveria fornecer ao projecto ontológico-fundamental o seu fundamento, por um lado, e, por outro, as expectativas desse mesmo projecto, quer no que diz respeito à destruição da tradição ontológica quer no que respeita à construção fenomenológica de ônticas regionais em geral, e daquilo a que Heidegger chama uma ôntica metafísica da existência (isto é: uma ôntica metafísica do próprio Dasein) em particular.

A análise preparatória do Dasein em Ser e Tempo surge na sequência daquilo a que Heidegger tinha chamado, nas suas primeiras lições, uma "hermenêutica da facticidade" a partir da qual, ultrapassando-se o preconceito de uma oposição entre a teoria e a prática, entre a filosofia e a vida fáctica, a atitude teórica se constituísse ela mesma como a expressão fáctica de uma vida que adquiriria propriamente uma maior consciência de si. Como se sabe, nas lições que desenvolvem esta hermenêutica da facticidade numa análise da "vida fáctica" ou da existência que desemboca em Ser e Tempo, o ente que existe facticamente - o Dasein - é analisado como um ente caracterizado por não poder ser adequadamente analisado como uma substância, como algo que simplesmente está aí presente-à-vista (como um Vorhandenes), determinado por qualidades - isto é: por categorias - que estejam nele presentes e que possam ser dele afirmadas

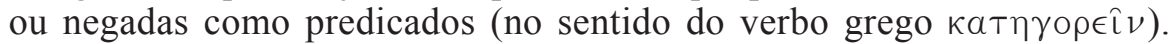
Como Heidegger afirma na conhecida frase de Ser e Tempo: «A "essência" do Dasein repousa na sua existência» ${ }^{9}$. E tal quer dizer que o Dasein não tem qualquer determinação prévia e subjacente à sua existência fáctica, ou seja, que ele é o que é precisamente ao existir e no existir. Por outras palavras: tal quer dizer que o Dasein é essencialmente ser-no-mundo ( $I n-$

${ }_{9}$ Sein und Zeit, p. 42. 
der-Welt-sein), marcado já sempre originariamente por um estar-lançado (uma Geworfenheit) neste mesmo mundo.

É a sua caracterização como originariamente ser-no-mundo que conduz toda a análise preparatória do Dasein que Heidegger empreende em Ser e Tempo. E esta análise gira em torno de três eixos. Em primeiro lugar, o mundo é aqui considerado como uma totalidade de remissões através da qual os entes que imediatamente se encontram se constituem como entes "à-mão", como Zuhandenen, com cuja lida o Dasein se encontra já sempre ocupado. Em segundo lugar, o ser-em do Dasein, nesta sua lida ocupada com o mundo, não se confunde com um estar dentro do mundo; o ser-em do ser-no-mundo é já sempre um estar-à-beira (um Sein-bei) do mundo, um estar sempre já a habitar o mundo e a lidar com entes no mundo, um estar já sempre nele disperso com a sua ocupação. Em terceiro lugar, se o Dasein, enquanto ser-no-mundo, está já sempre nele disperso, se ele é originariamente uma dispersão no mundo, tal quer dizer que ele é originariamente não ele mesmo, mas a mera indiferença perdida nos outros que "a gente" (das Man) constitui. A análise da "gente" como resposta à pergunta pelo ser do Dasein, em Ser e Tempo, é muito conhecida: «A gente é no modo da não-autonomia [Unselbständigkeit] e da inautenticidade [Uneigentlichkeit] ${ }^{10} ;$ «O si-mesmo do Dasein quotidiano é a gente ela mesma, que diferenciamos do si-mesmo autêntico, isto é, captado propriamente. Enquanto a gente ela mesma, o respectivo Dasein está disperso na gente e tem de se encontrar. Esta dispersão caracteriza o "sujeito" do modo de ser que conhecemos como o emergir preocupado no mundo que se nos encontra próximo»» ${ }^{11}$. Passagens como estas tornam claro que a análise da "gente" por Heidegger deriva da consideração de uma alienação primordial do Dasein em relação a si mesmo, de uma dispersão originária colocada por Heidegger no núcleo mais originário e essencial desse mesmo Dasein. É este carácter originário da dispersão (Zerstreuung) que conduz Heidegger a encontrar numa Streuung, numa dispersão originária a origem da própria existência fáctica do Dasein e, nessa medida, a fonte mesma de que brotam os elementos básicos da sua vida fáctica concreta: a sua própria corporeidade e sexualidade. Como escreve Heidegger em 1928: «O Dasein em geral alberga a possibilidade interior da dispersão fáctica na corporeidade e, com isso, na sexualidade. [...] Por outras palavras: à essência do Dasein em geral pertence já, segundo o seu conceito metafisicamente neutro, uma dispersão [Streuung] originária que, numa perspectiva muito determinada, é dispersão [Zers-

\footnotetext{
10 Ibid., p. 128.

11 Ibid., p. 129.
} 
treuung] $\gg^{12}$. E é a partir desta originariedade da dispersão que se torna possível a Heidegger descrever o modo como o Dasein existe, enquanto "ser-aí", como um decair (Verfallen) e, nesse sentido, como um estar já sempre ausente desse mesmo ser-aí. Como formulará nas lições de 1930: «Da essência do Dasein faz parte, ao limite, este ser-ausente. Isso não é um evento qualquer que surge ocasionalmente, mas é um carácter essencial do próprio ser humano, um como segundo o qual ele é, de tal modo que o homem, enquanto existir, está também já sempre e necessariamente, no seu Dasein, de algum modo ausente» ${ }^{13}$.

A caracterização do Dasein como originariamente disperso, e como sendo, à partida, não ele mesmo, mas a gente, está na base daquilo a que poderíamos chamar o matiz fundamental de que o conceito heideggeriano de "inautenticidade" ou de "impropriedade" (Un-eigentlichkeit), em Ser e Tempo, se reveste. A formação deste conceito tem na sua origem a ideia de que a dispersão originária do Dasein não poderia deixar de se traduzir numa modalidade - Heidegger refere-se a esta modalidade através do termo latino modus - ou num modo concreto de existir. Enquanto modus da existência, a inautenticidade é apresentada por Heidegger como uma possibilidade existencial do Dasein. No entanto, enquanto possibilidade, esta inautenticidade aparece aqui como a própria tradução concreta, numa modalidade existencial, da dispersão originária do Dasein, ou seja, como o modus que emerge como a ratio cognoscendi do próprio ser do Dasein na medida em que este surge como um ente cujo ser, estando já sempre disperso e lançado no mundo, é a própria ratio essendi da inautenticidade. Em Ser e Tempo, na sua análise preparatória do Dasein, Heidegger é claro quanto ao estatuto que assim a inautenticidade adquire. A autenticidade do Dasein é apresentada não como uma alternativa à dispersão que marca a sua existência fáctica, mas como apenas uma sua modificação: «A existência autêntica não é nada que paire acima da quotidianeidade decadente, mas é existentivamente apenas um captar modificado desta» ${ }^{14}$. Neste sentido, não sendo a autenticidade uma alternativa à dispersão enquanto modo de ser, a inautenticidade aparece caracterizada por Heidegger como uma modificação da autenticidade não na medida em que apontaria para um possível modo fáctico de existir entre outros modos fácticos de existir, mas na medida em que o conceito de inautenticidade traduz em diferentes modi o modo como o próprio Dasein existe e se concretiza num plano fáctico e concreto. Como conclui Heidegger: «Mostra-se que, em primeiro

12 Metaphysische Anfangsgründe der Logik im Ausgang von Leibniz, p. 173.

13 Grundbegriffe der Metaphysik. Welt - Einsamkeit - Endlichkeit, Gesamtausgabe, vols. 29/30, Frankfurt, Vittorio Klostermann, 1992, p. 95.

14 Sein und Zeit, p. 179. 
lugar e quase sempre, o Dasein não é ele mesmo, mas perdeu-se na própria gente. Esta é uma modificação existencial do si-mesmo autêntico» ${ }^{15}$.

Assim, se o conceito de inautenticidade assinala, em Ser e Tempo, a modificação pela qual se traduz concretamente o ser do Dasein enquanto ser-no-mundo, tal quer dizer que a análise preparatória do Dasein teria conduzido Heidegger ao reconhecimento da existência do Dasein, naquilo a que anteriormente Heidegger teria chamado a sua "vida fáctica", como sempre já marcada pela inautenticidade que traduz concretamente o estar-lançado no mundo. É nesse sentido que Heidegger afirma, em Ser e Tempo, que «o Dasein é, à partida, a gente, e quase sempre permanece assim» ${ }^{16}$. E é também neste sentido que Heidegger se referirá à autenticidade não como uma decisão ou uma tomada de consciência teórica, mas como a emergência fugaz de uma simples tonalidade afectiva que «é possível e também real - embora suficientemente rara - apenas por instantes na disposição fundamental da angústia ${ }^{17}$. É então a partir da noção de que a análise preparatória do Dasein, preparada por Ser e Tempo, não poderia deixar de conduzir Heidegger a pensar a inautenticidade do Dasein como a pura e simples tradução concreta da dispersão originária deste mesmo Dasein, na sua constituição ontológica como ser lançado no mundo, que se torna possível encontrar o ponto de incompatibilidade entre esta mesma análise preparatória, por um lado, e as expectativas de Heidegger em torno do projecto da ontologia fundamental, por outro.

Regressemos, então, às expectativas do projecto na sua dupla dimensão destrutiva e construtiva. A tarefa destrutiva a que o projecto da ontologia fundamental se deveria dedicar, ou seja, a tarefa de uma confrontação com a tradição ontológica ocidental, deveria dar lugar, na perspectiva de Heidegger, a uma renovação da própria filosofia. É este o sentido com que Heidegger conclui da sua abordagem do projecto ontológico-fundamental como um todo que «está aí o instante, precisamente na desolação da situação filosófica que é pública, de voltar a ousar a passagem para a metafísica autêntica, isto é, de a desenvolver a partir do solo» ${ }^{18}$. E a necessidade desta renovação filosófica é evocada por Heidegger frequentemente ao longo das suas lições. É no sentido desta renovação que ele alude ao carácter infundado da distinção entre "atitude teórica" e "vida fáctica" logo desde as primeiras lições que dá em Freiburg. É tendo em conta esta renovação que ele menciona a necessidade de ultrapassar a

15 Ibid., p. 317.

16 Ibid., p. 129.

17 "Was ist Metaphysik?", in Wegmarken, Gesamtausgabe, vol. 9, Frankfurt, Vittorio Klostermann, 1976, p. 111.

18 Metaphysische Anfangsgründe der Logik im Ausgang von Leibniz, p. 165. 
separação disciplinar dos saberes, dispersos por totalidades fechadas e abstraídas do seu fundamento, a partir de um renovado enraizamento no fundamento metafísico que a análise da existência do Dasein poderia fornecer: «Só quando a ciência existir a partir da metafísica é que ela consegue adquirir de um modo constantemente novo a sua tarefa essencial, a qual não consiste em coleccionar e ordenar conhecimentos, mas na abertura, que sempre de novo se tem de cumprir, de todo o espaço da verdade de natureza e história» ${ }^{19}$. E é igualmente este o significado de, já como reitor, em 1933, Heidegger aludir à necessidade de as ciências se voltarem para o seu início grego, compreendendo que estas não podem constituir especialidades disciplinares separadas e abstraídas da vida e que

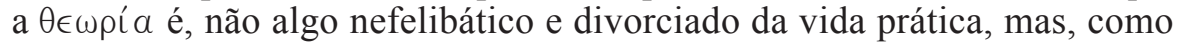
dirá por ocasião da tomada de posse do reitorado, «a suprema efectivação da praxis genuína» ${ }^{20}$.

Por seu lado, a construção fenomenológica a que a análise preparatória do Dasein deveria dar lugar, segundo o projecto exposto nas lições de 1928, teria por conteúdo inevitável uma ontologia regional ou uma "ôntica metafísica" do Dasein, em cujo âmbito deveria caber, como Heidegger afirma explicitamente, «a questão da ética» ${ }^{21}$. Em Ser e Tempo, através das tentativas de atribuir uma configuração concreta ao conceito de autenticidade, Heidegger dá já indicações básicas sobre o caminho que uma ética proveniente do projecto ontológico-fundamental deveria seguir. A assunção pelo Dasein do seu si-mesmo enquanto ser-no-mundo, a resolução (Entschlossenheit) que corresponde a uma abertura autêntica (eigentliche Erschlossenheit) da existência do Dasein no mundo, longe de corresponder a uma fuga mundi ou a um isolamento deste Dasein no seu "eu", consiste antes numa relação transformada com os outros e com os entes intramundanos em função dessa mesma assunção resoluta. Como escreve Heidegger: "O "mundo" à-mão não se torna outro quanto ao "conteúdo", o círculo dos outros não é mudado, e, no entanto, o ser compreendedor e preocupado para com o à-mão e o ser-com solícito com os outros é agora determinado a partir do mais próprio poder-ser-si-mesmo» ${ }^{22}$. É sobretudo diante dos outros que a autenticidade do Dasein se pode manifestar. É assim que, falando da relação do Dasein com os outros, Heidegger evoca um cuidado autêntico (eigentliche Sorge) e uma ligação autêntica (eigentliche Verbundenheit) caracterizados pela atitude contrária

19 "Was ist Metaphysik?", Wegmarken, Gesamtausgabe, vol. 9, p. 121.

20 "Die Selbstbehauptung der deutschen Universität", Reden und andere Zeugnisse eines Lebensweges, Gesamtausgabe, vol. 16, Frankfurt, Vittorio Klostermann, 2000, p. 110.

${ }^{21}$ Cf. Metaphysische Anfangsgründe der Logik im Ausgang von Leibniz, p. 199.

22 Sein und Zeit, pp. 297-298. 
à tendência para os dominar (beherrschen) e para se lhes substituir (einspringen); longe de "saltar para o seu lugar", esta atitude é caracterizada por Heidegger precisamente como a atitude antecipativa-libertadora daquele que «ajuda o outro a tornar-se para si, no seu cuidado, transparente e a libertar-se para ele» ${ }^{23}$. É também evocando uma "ligação autêntica" com os outros que Heidegger alude à necessidade de a resolução corresponder a uma decisão (Entschluss) concreta: "A assunção resoluta do "aí" fáctico próprio significa, ao mesmo tempo, a decisão para a situação» ${ }^{24}$. E esta decisão para a situação conhece aqui, já em Ser e Tempo, uma descrição suficientemente concreta: «Só na partilha e no combate é que o poder do destino [Geschick] se liberta. O destino fadado do Dasein na e com a sua "geração" constitui o acontecer pleno, autêntico do Dasein» ${ }^{25}$.

São sobretudo as considerações de Ser e Tempo em torno daquilo que seria uma existência autêntica do Dasein que tornam manifesta a incongruência entre a "hermenêutica da facticidade" do Dasein, por um lado, e, por outro, os resultados esperados do projecto da ontologia fundamental, quer no que toca ao seu momento destrutivo quer no que toca ao seu momento construtivo. A partir do momento em que uma tal incongruência se tornasse clara, Heidegger não poderia deixar de procurar reler a sua análise (meramente preparatória) do Dasein no sentido de a tornar adequada a um projecto filosófico que se caracterizaria quer pela expectativa da fundação de uma "era" filosófica - Heidegger fala explicitamente de um "tempo" - marcada pela confrontação com a tradição quer pela expectativa da sua articulação com uma abordagem do humano na qual a "questão da ética", ou seja, o tema daquilo a que Ser e Tempo chama a resolução, possa encontrar um fundamento satisfatório. É em larga medida a esta releitura dos conceitos fundamentais de Ser e Tempo que Heidegger procede ao longo da década de 1930.

Mas em que medida esta releitura de Ser e Tempo na década de 1930 permite a Heidegger o cumprimento das suas expectativas? O fio condutor desta releitura pode ser identificado, como vimos, num passo simples: se todo o projecto de constituição de uma ontologia fundamental deveria estar baseado numa "hermenêutica da facticidade" que proporcionasse uma análise do Dasein, mas se se levasse às últimas consequências a noção de que o Dasein é, não um sujeito, mas o próprio ser no seu "aí", então o Dasein não seria na sua compreensão do ser senão o próprio ser no "aí" da sua compreensão, isto é, na apropriação daquele que o compreende. A relação do ser com o ser-aí que o pensa consiste na abertura para este

\footnotetext{
23 Ibid., p. 122.

24 Ibid., pp. 382-383.

25 Ibid., pp. 384-385.
} 
mesmo ser-aí de um jogo de espaço-tempo (Zeitspielraum) que à partida o enquadra e que, nessa medida, constitui o seu mundo. E neste sentido que Heidegger começará a falar, a partir daqui, numa de-cisão primordial pela qual o ser abre para o Dasein o seu próprio mundo. E dizer que o ser funda uma de-cisão primordial na qual o Dasein já sempre se encontra, encontrando-se assim lançado num "jogo de espaço-tempo" aberto por essa decisão, corresponde, no fundo, à produção de duas afirmações a partir das quais a análise do Dasein em Ser e Tempo vai ser profundamente transformada.

Em primeiro lugar, a afirmação desta de-cisão originária corresponde à afirmação de que o mundo em que o Dasein está lançado, enquanto ser-no-mundo, não é $o$ mundo, mas um mundo. Os conceitos fundamentais que Heidegger tematizará no início da década de 1930 - o conceito de finitude e de verdade - são abordados precisamente no sentido de providenciar esta transformação do conceito de mundo. Em segundo lugar, afirmar que o homem, enquanto ser-aí, está confrontado com uma de-cisão primordial cuja origem se encontra no próprio ser significa inevitavelmente dizer que o homem está confrontado com o ser como um dilema, ou seja, significa afirmar que, diante do mundo aberto pelo ser, o homem nunca está por ele determinado, sendo sempre, nessa medida, chamado a uma decisão originária traduzível na forma dilemática de uma disjunção, de um "ou-ou". Por outras palavras: dizer que o ser é uma de-cisão significa, pela negativa, dizer que ele não é uma pura e simples determinação.E aquilo que através dele é posto para decisão é sempre, antes de mais, a decisão sobre a sua subtracção e esquecimento, por um lado, ou a sua assunção e decisão, por outro. Tal quer dizer, noutros termos, que, a partir da de-cisão primordial do ser, o homem, enquanto ser-aí, nunca está determinado ou necessitado por um fado (Schicksal) que se lhe ofereça como uma fatalidade, mas está, ao invés, em virtude dessa sua não determinação, interpelado por um dilema que sempre se lhe envia como um destino (Geschick): o dilema de ou se satisfazer com o seu mundo, com um mundo que lhe é dado e cujo questionamento, nessa medida, se lhe subtrai e é esquecido, ou ousar este mesmo questionamento, assumindo o risco de, contrapondo-se à tradição, contribuir para um "outro início" ainda impronunciável, diante do "primeiro início" que a tradição constitui. É neste sentido que, diante da tradição filosófica ocidental, Heidegger enumera as "decisões" com as quais o homem está confrontado: «Se o homem quer permanecer "sujeito" ou se funda o ser-aí; [...] se o homem ousa o Ser e, com isso, o declínio, ou se ele se satisfaz com o ente; se o homem em geral ainda ousa a decisão ou se ele se entrega à indecisão que está próxima da era enquanto estado da suprema "actividade". Todas estas decisões, 
que, segundo a aparência, são muitas, reúnem-se numa única: se o Ser se subtrai definitivamente ou se esta subtracção se torna na recusa da primeira verdade e no outro início da história ${ }^{26}$. O percurso filosófico de Heidegger na década posterior à publicação de Ser e Tempo pode, então, ser compreendido como uma tentativa de fundar estas duas afirmações, as quais poderiam conduzir à transformação da análise do Dasein no sentido da viabilização das expectativas que a análise preparatória da existência se encarregará de frustrar.

A primeira das afirmações que mencionámos - a afirmação do mundo não como $o$ mundo, mas como um mundo - começa a ser preparada por Heidegger imediatamente após a publicação de Ser e Tempo, no período que medeia entre 1927 e a publicação de Kant e o Problema da Metafísica, em 1929. Como se sabe, nestes dois anos, o conceito de finitude adquire um estatuto cada vez mais determinante do ser do próprio Dasein, de tal modo que, na obra de 1929, poder-se-ia dizer que o Dasein deixa de ser apresentado, enquanto ser-no-mundo, como uma abertura ao mundo marcada pela finitude para passar a ser assinalado, na sua origem mesma, como uma finitude originária que, no entanto, se abre ao mundo. É a partir da referência a esta aquisição pela finitude de um estatuto nuclear e originário na determinação do ser do homem que se pode compreender a conhecida frase de Heidegger em Kant e $o$ Problema da Metafísica: «Mais originário que o homem é a finitude do Dasein nele» ${ }^{27}$. E é a partir deste enraizamento da finitude no próprio núcleo mais originário do ser do homem que se pode compreender que Heidegger comece a falar numa não-verdade (Un-wahrheit) originária, enraizada na própria essência da verdade como desencobrimento ( $U n$ verborgenheit ${ }^{28}$. Se na essência da verdade, enquanto desencobrimento do ente na abertura do Dasein, está uma co-originária não-verdade, tal quer dizer que o próprio desencobrimento da verdade pode ser pensado como o acontecer de uma história. E é a partir desta abordagem do desencobrimento como uma história em que o encobrimento é sempre co-originário que se torna possível a Heidegger falar não do mundo, mas de $u m$ mundo fundado justamente numa história face à qual é sempre possível a emergência de um “outro início". É também por causa disso que Heidegger poderá falar do mundo como o mundo de uma terra, ou seja, como um mundo que, como Heidegger escreverá no seu conhecido ensaio de 1935 sobre A Origem da Obra de Arte, «só

\footnotetext{
${ }^{26}$ Beiträge zur Philosophie, GA65, pp. 90-91.

${ }^{27}$ Kant und das Problem der Metaphysik, Frankfurt, Vittorio Klostermann, 1998, p.

${ }^{28}$ Cf."Vom Wesen der Wahrheit", in Wegmarken, pp. 193 ss.
} 229. 
se funda na terra na medida em que a verdade acontece como combate originário de clareira e encobrimento» ${ }^{29}$.

Por seu lado, a afirmação do homem como confrontado com o ser - ou seja, com o seu mundo - enquanto não determinado por ele, isto é, a afirmação deste mesmo homem enquanto sempre chamado pelo ser a uma decisão dilemática, começa a ser elaborada explicitamente no momento em que, a partir da consideração da verdade como história do mundo como um mundo (e não $o$ mundo), Heidegger se começará a referir a um início (Anfang) da história do ser irredutível a um mero começo (Beginn). Se o mundo é já não o mundo, mas um mundo, tal quer dizer que o mundo no qual o homem se encontra se funda numa determinada decidão originária que constitui, nessa medida, o seu princípio arquetípico ou, o que é o mesmo, o seu início. Assim, num mundo em que este início se obscurece e se perde, ficando para trás como um mero começo, o início permanece diante do homem como a evocação de que este mesmo homem, enquanto ser-aí, nunca é determinado pelo seu mundo e pela sua situação nele, mas antes colocado pelo ser, enquanto de-cisão originária, numa decisão dilemática. É neste sentido que Heidegger, em vários textos do começo da década de 1930, se refere ao início como um apelo para que o homem, não aceitando a determinação do seu mundo, recupere a partir desse início aquilo a que Heidegger chama a sua grandeza. Como Heidegger diz claramente, por exemplo, aquando da sua assunção do reitorado: «O início ainda é. Ele não repousa atrás de nós, como aquilo que foi há muito, mas está diante de nós. $\mathrm{O}$ início, enquanto aquilo que é maior, já passou previamente sobre tudo aquilo que é vindouro e, assim, também já sobre nós. O início entrou no nosso futuro, ele está lá sobre nós, como a ordem longínqua para retomar a sua grandeza» ${ }^{30}$. E é com o intuito de assinalar explicitamente a não determinação do homem pelo seu mundo e pela sua situação, e de assinalar também a constituição do ser como uma de-cisão primordial, de-cisão essa que, longe de o determinar, destina o homem a uma decisão insuperável e irredutível, que Heidegger se dedica, a partir de 1932, a um estudo minucioso de $O$ Trabalhador de Ernst Jünger, contrapondo-se à tese fundamental enunciada por este: a tese de que, num mundo totalmente configurado pela figura do trabalhador e pela "mobilização total" de um carácter total de trabalho (totaler Arbeitscharakter), a única

29 "Der Ursprung der Kunstwerke", in Holzwege, Frankfurt, Vittorio Klostermann, 1994 , p. 42 [trad. port.: p. 56].

30 "Die Selbstbehauptung der deutschen Universität", Reden und andere Zeugnisse eines Lebensweges, Gesamtausgabe, vol. 16, p. 110. 
atitude possível seria "participar e servir» ${ }^{31}$, assumindo aquilo a que Jünger chama a atitude de um "realismo heróico".

$\mathrm{Na}$ sua análise do trabalho como figura determinante de um mundo que se torna totalmente mobilizado, a análise de Jünger procurará mostrar como a mobilização total do mundo tem como consequência o estreitamento das possibilidades humanas, reduzindo-as a uma única decisão: a decisão de participar no próprio movimento de mobilização e tornar-se, nessa medida, no próprio sujeito que a domina. Diante desta participação, qualquer alternativa consistiria não propriamente numa decisão, mas numa fuga romântica caracterizada pelo afastamento do mundo e por um protesto contra a realidade efectiva: «Do mesmo modo que o espaço romântico aparece no afastamento, com todas as características da miragem, assim a atitude romântica aparece como protesto. [...] Tudo isto são formas de fuga em que o singular, depois de ter percorrido a circunvalação do mundo espiritual e corporal em busca de uma saída, depõe as armas» ${ }^{32}$. E é precisamente em confrontação com esta análise jüngeriana que Heidegger tem a oportunidade de, contrapondo-se-lhe explicitamente, assinalar o homem como nunca determinado pelo ser, e como sempre chamado a uma decisão livre diante da de-cisão originária do ser fundadora do seu mundo. $\mathrm{O}$ estudo exaustivo da relação de Heidegger com Jünger - o estudo que a publicação do volume 90 das Obras Completas de Heidegger finalmente permite - está ainda por fazer. No entanto, os traços fundamentais da leitura intensa que Heidegger faz de $O$ Trabalhador providenciam uma imediata clareza em torno da tentativa de Heidegger de, através da leitura de Jünger e da sua contraposição ao "realismo heróico" jüngeriano, fornecer a base para a afirmação do homem como indeterminado pela de-cisão originária do ser e, nessa medida, como chamado a uma decisão irredutível, cuja irredutibilidade o manifesta como não determinado pelo mundo em que se encontra. É assim que, se Jünger estabelece o "realismo heróico" como a única alternativa possível de homens dominadores do mundo, configurados com a figura do trabalhador e alheios a uma alienação romântica, Heidegger afirma claramente, nos seus seminários sobre Jünger, que «os "senhores" são os escravos do abandono do ente pelo ser»" ${ }^{33}$ e que um tal realismo constitui uma prisão que «condiciona a impotência da decisão e meditação e, com isso, do "domínio"»"34; e

${ }^{31}$ Cf. Ernst Jünger, O Trabalhador (trad. Alexandre Franco de Sá), Lisboa, Hugin, 2000, p. 266.

${ }^{32}$ Ibid., p. 80.

${ }^{33} \mathrm{Zu}$ Ernst Jünger, Gesamtausgabe, vol. 90, GA90, Frankfurt, Vittorio Klostermann, 2004, p. 31.

${ }^{34}$ Ibid., p. 85. 
acrescenta: «O simples sim - a pura capitulação diante da realidade ${ }^{35}$. Se para Jünger a liberdade é apresentada como a capacidade de o homem se configurar de acordo com a figura do trabalhador e, através disso, de dominar a mobilização total do mundo através do trabalho, para Heidegger, pelo contrário, a liberdade estaria precisamente na capacidade de se diferenciar em relação ao processo de mobilização pelo poder. Como escreve Heidegger: «O senhor é aquele que domina sobre o poder. O simples sim ao poder enquanto essência da realidade é a mais baixa servidão. Senhor do poder é aquele que transforma a sua essência. Tal transformação brota apenas do Ser» ${ }^{36}$.

E é também assim que, se Jünger representa a configuração do homem sob a figura do trabalhador como a emergência de uma nova era histórica, uma tal configuração não aparece a Heidegger senão como a consumação intensiva de toda a história tal como foi até então: «Este futuro é a finalização planetária de um fim. À agudeza do olhar para este fim corresponde a ilusão sobre a essência desta história que em vão deve ser falsificada, convertendo-se de fim em início e em "algo novo" $\rangle^{37}$. Assim, se Jünger pensa a mobilização total a partir da metafísica nietzschiana da vontade de poder, e se a decisão fundamental desta metafísica, longe de ser questionada ${ }^{38}$, é apenas afirmada como um destino fatal, dir-se-ia que a leitura de Jünger por Heidegger se orienta precisamente no sentido de apresentar o homem como chamado pelo ser a uma decisão que o torna irredutível ao seu mundo; ou seja, no sentido de apresentar a possibilidade sempre presente no homem ocidental de contribuir, diante do mundo da metafísica moderna consumada, para um "outro início" da história. É desta permanente possibilidade que faz parte, numa filosofia da acção, a exigência permanente de uma assunção resoluta pelo homem da sua situação própria sem que tal ponha em causa a possibilidade de um retraimento (Verhaltenheit), ou seja, sem que tal signifique que este se deixe pura e simplesmente determinar (isto é: pura e simplesmente mobilizar) pelo seu mundo. A leitura por Heidegger da obra de Jünger, no início da década de 1930, torna-se assim no melhor indício de que, com a releitura de Ser e Tempo e o abandono do modo como nele se desenvolve a análise do Dasein, se tratava não propriamente do abandono do projecto ontológico-fundamental, mas de contribuir para a viabilização daquilo que tinham sido as suas mais elevadas expectativas.

\section{Ibid.}

36 Die Geschichte des Seyns, Gesamtausgabe, vol. 69, Frankfurt, Vittorio Klostermann, 1998, p. 21.

37 Zu Ernst Jünger, p. 74.

${ }^{38}$ Cf. Ibid., p. 57. 